\title{
Shelf Life of Artocarpus lowii King's Seeds And Its Viability
}

\section{Frisca Damayanti and Fitri Fatma Wardani}

Center for Plant Conservation Botanic Gardens - The Indonesian Institute of Science Jl. Ir. H. Juanda 13 Bogor, Indonesia 16003

\section{Abstract}

Artocarpus lowii King is a species of Moraceae family members. This species is widely utilized by people as food, medicine, and timber. A. lowii is propagated by seed. $A$. lowii seeds belong to the recalcitrant seeds, which have a short shelf life. Therefore, it is necessary to find the right storage method for storing $A$. lowii seeds, in order that A. lowii seed has longer shelf life. The purpose of this study was to determine the viability $A$. lowii with storage time treatments and find the efficient storage method. A. lowii seeds were stored by covering the seeds with mosses in a jar. It was taken 40 seeds every week for viability test. The 30 seeds have planted in the sand media and 10 seeds for grain moisture content calculations. Results of this study were water content of $A$. lowii seed on o wk to 7 wk increased, and the viability of $A$. lowii seeds have still high enough to $9 \mathrm{wk}$ around $60 \%$. Therefore, seed storage methods using mosses can be used as an alternative to extend the shelf life of $A$. lowii seed.

Corresponding Author: Frisca Damayanti friscad@yahoo.com

Received: 11 February 2017 Accepted: 08 March 2017

Published: 26 March 2017

Publishing services provided by Knowledge $\mathrm{E}$

(a) Frisca Damayanti and Fitri Fatma Wardani. This article is distributed under the terms of the Creative Commons

Attribution License, which permits unrestricted use and redistribution provided that the original author and source are credited.

Selection and Peer-review under the responsibility of the ICBS Conference Committee.

\section{G OPEN ACCESS}

Keywords: Artocarpus lowii King; recalcitrant seed; storage media.

\section{Introduction}

Artocarpus lowii is one of the species in the Moraceae family. It is widely used by people as food, medicine, and timber [1]. For its potential benefits, it needs to be propagated to sustain its life cycle. Considering the decreased of cultivated land, one of the Artocarpus genus propagation method is by seed [2,3]. A. lowii seeds belong to the recalcitrant seeds, which have a short shelf life [2]. Recalcitrant seeds tend to lose their viability over a longer storage time [4]. So after harvesting period, they should be treated immediately. Therefore, it is necessary to find appropriate and efficient storage method for $A$. lowii seeds, so they have a longer shelf life. The purposes of this research are to find an efficient storage method for $A$. lowii seeds and know its viability with various storage duration treatments.

\section{Material and Methods}

Artocarpus lowii seeds were taken from trees collection of Botanical Center for Plant Conservation-LIPI with physiological maturity condition. This research was conducted 


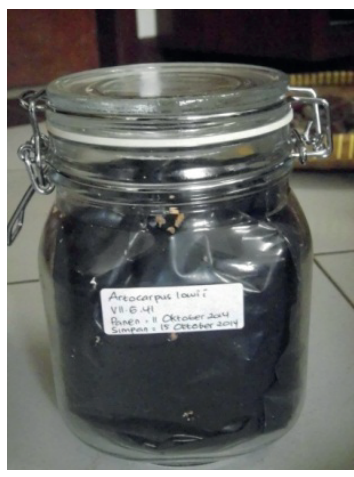

(a)

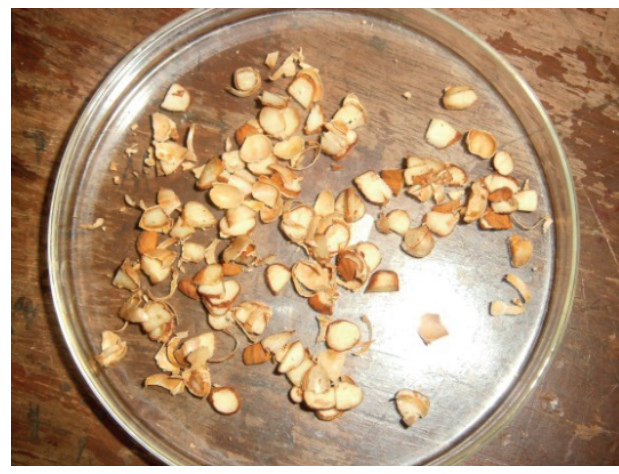

(b)

Figure 1: (a) Glass jar containing moss media; (b) Slice of $A$. lowii seeds.

in the Seeds Bank's greenhouse, Center for Plant Conservation Botanical Gardens-LIPI in October 2014 until December 2014.

The seeds that have been cleaned, stored in a glass jar containing moss. The seeds were stored for 3 mo. Every week the seed of $A$. lowii were taken 40 seeds, 30 seeds were germinated and 10 seeds were used to determinate the water content. Measurements of water content used drying method. Petri dish that will be used for the measurement of water content were heated in the oven $130^{\circ} \mathrm{C}$ for $30 \mathrm{~min}$ to $60 \mathrm{~min}$. In other hand, the seeds were smashed or thinly sliced. Then the petri dish was weighed to get the weight of the cup (M1). The sliced seeds were put into a petri dish to obtain the initial weight of the seeds $\left(M_{2}\right)$. Then the seeds were put into the oven with the temperature $105^{\circ} \mathrm{C}$ for $18 \mathrm{~h}$. After $18 \mathrm{~h}$, the seeds and the petri dish were weighed to obtain the final weight of beans $\left(M_{3}\right)$. Methods of storage treatment and measuring the water content refer to Figure 1 . The water content can be obtained from the formula:

$$
\text { Water content }=\frac{M_{3}-M_{1}}{M_{2}-M_{1}} \times 100 \%
$$

The experimental design of the research used completely randomized design (CRD) one factorial. Thirty seeds were germinated on the sand media every week. Parameters measured were seed viability and seedling characteristics. Seed viability parameters can be obtained from the formula:

$$
\text { Viability : } \frac{\text { number of germinated seed }}{\text { number of planted seed }} \times 100 \%
$$

Seedling taken from each treatment were washed with water and dried, after that, seedling were characterized. Radicle length, epicotyl length, number of leaves, fresh weight and dry weight were measured. For the measurement of the final weight of seedlings, seedlings were put in the oven with a temperature $60^{\circ} \mathrm{C}$ for $72 \mathrm{~h}$. Data were analysed using Analysis of Variance, the software used was Statistical Tool for Agricultural Research (STAR Nebula). 


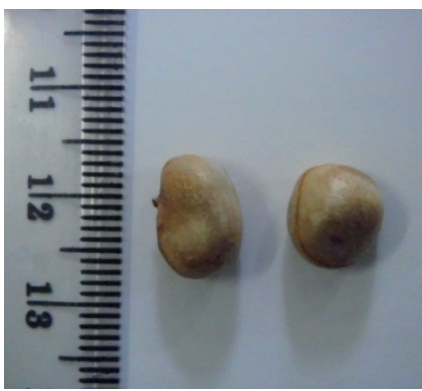

(a)

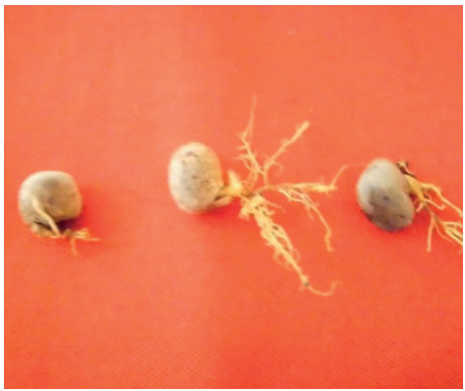

(b)

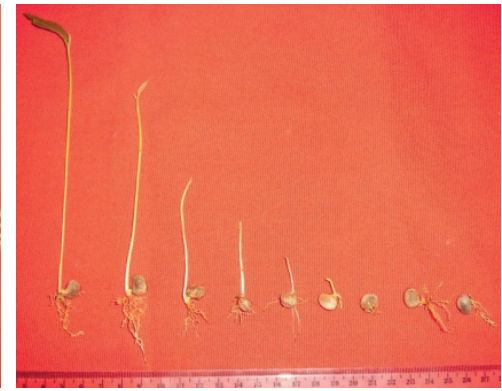

(c)

Figure 2: (a) A. lowii seeds; (b) Seed begin to germinate; (c) Germination pattern of $A$. lowii.

\section{Result and Discussion}

(A) lowii seed have round to oval shaped. The color of $A$. lowii seeds is brownish white. The average of weight was $0.3 \mathrm{~g}, 9.8 \mathrm{~cm}$ in length, and $6.1 \mathrm{~cm}$ in diameter. The seeds have water content about $27.25 \%$. A. lowii seeds belong to the recalcitrant seeds [2]. Therefore, the aim of this research is to get efficient storage methods using moss to maintain its viability. The seeds, seeds begin to germinate and germination pattern of $A$. lowii refer to Figure 2.

The factors can maintain the viability of the seed during storage, especially in recalcitrant seeds, such as temperature, humidity, moisture content of the seeds and the container store [5]. According to King and Roberts [6], storage conditions that must be considered for recalcitrant seeds, such as preventing of drying, pressing microbial contamination, prevent germination and maintain an adequate supply of oxygen. $A$. lowii seeds stored in glass jars containing media moss to keep moisture of seeds. The humidity of storage container was high, it will maintain water levels in the seed.

Table 1 is showed that seed viability of $A$. lowii which stored in glass jar with moss media from $1 \mathrm{wk}$ until $10 \mathrm{wk}$ were still high. It indicates that the length of the seeds stored in glass jar containing moss does not affect the viability of the seed. The highest viability of $A$. lowii contained in seeds stored at the $4 \mathrm{wk}$. A. lowii seed viability did not decrease significantly until $10 \mathrm{wk}$. The viability of $A$. lowii seed had remained high due to the water content of seeds was still at high too. In addition, the seeds germinated in a suitable environment for growth, it germinated in greenhouse which the condition of light, temperature, oxygen, and water were well. According to Pennstate [7], the factors affecting germination are water, oxygen, temperature, and light.

The moisture content of $A$. lowii seed did not decrease on the treatment of seed storage, even the seed moisture content tended to increase from week to week. The high of water content in the seed because the seed of $A$. lowii was stored in sealed glass jars containing moss media that have a fairly high humidity. 


\begin{tabular}{l|c|c|c}
\hline Time & Water content (\%) & Number of germination (seed) & Viability (\%) \\
\hline Wk-1 & $27.25 d$ & 22 & 73.33 \\
\hline Wk-2 & $28.71 d$ & 17 & 56.67 \\
\hline Wk-3 & $38.52 b c$ & 20 & 66.67 \\
\hline Wk-4 & $35.62 \mathrm{~cd}$ & 27 & 90.00 \\
\hline Wk-5 & $33.20 d$ & 25 & 83.33 \\
\hline Wk-6 & $34.47 \mathrm{~cd}$ & 24 & 80.00 \\
\hline Wk-7 & $41.16 \mathrm{ab}$ & 19 & 63.33 \\
\hline Wk-8 & $42.07 \mathrm{a}$ & 21 & 70.00 \\
\hline Wk-9 & $36.47 \mathrm{~cd}$ & 17 & 56.67 \\
\hline Wk-10 & $40.66 \mathrm{ab}$ & 18 & 60.00 \\
\hline
\end{tabular}

Information: The same letter indicates no significant difference in the level 5\% at DMRT test.

TABLE 1: Water content and seed viability of $A$. lowii.

\begin{tabular}{|c|c|c|c|c|c|}
\hline Time & Radicle $(\mathrm{cm})$ & Epicotyl (cm) & Number of leave (unit) & Fresh weight (g) & Dried weight (g) \\
\hline Wk-1 & 4.52 & 14.12 & $2.6 \mathrm{~b}$ & $0.81 C$ & $0.21 a b c$ \\
\hline Wk-2 & 6.40 & 15.98 & $3 b$ & $1.13 a b$ & $0.27 a$ \\
\hline Wk-3 & 4.94 & 16.24 & $3 b$ & $0.92 b c$ & $0.21 a b c$ \\
\hline Wk-4 & 5.10 & 16.40 & $2.8 \mathrm{~b}$ & $1.01 a b c$ & $0.15 \mathrm{~cd}$ \\
\hline Wk-5 & 3.78 & 16.72 & $3 b$ & $0.70 b c$ & $0.14 \mathrm{~d}$ \\
\hline Wk-6 & 4.40 & 17.70 & $3.6 a$ & $1.30 a$ & $0.23 a b$ \\
\hline Wk-7 & 5.80 & 15.30 & $3 b$ & $0.96 \mathrm{bc}$ & $0.21 a b c$ \\
\hline Wk-8 & 4.80 & 14.50 & $3 b$ & $0.81 c d$ & $0.23 a b$ \\
\hline Wk-9 & 6.50 & 14.58 & $3 b$ & $0.96 \mathrm{C}$ & $0.15 \mathrm{~cd}$ \\
\hline Wk-10 & 3.14 & 15.40 & $3 b$ & $0.87 b c$ & $0.18 b c d$ \\
\hline
\end{tabular}

TABLE 2: Characteristics of seedling A. lowii.

Moss is a medium which is derived from a kind of Bryophyte, namely Sphagnum. Moss is able to absorb water and retain water very well, and it is able to maintain the humidity in the media. Moss has much cavities, it has good drainage and aeration [8]. Therefore, the seeds were stored in a jar containing moss will retain moisture, the moisture content in the seeds is not reduced, and the seed viability remain high, despite it has been stored for 3 mo.

Table 2 is looked the characteristics of seedling that grows on time variety of planting. Radicle, epicotyl, number of leaves, fresh weight and dry weight quality was not decrease. It indicates that $A$. lowii treated seed storage duration had produced good 
seedling results. Storage duration was not too affected in radicle, epicotyl length, number of leaves, fresh weight and dry weight.

\section{Conclusion}

From this study, it can be concluded that $A$. lowii seed had good viability even when it was given treatment storage duration, this is because the water content in seeds $A$. lowii was maintained up to the $10 \mathrm{wk}$ of storage. The characteristic of seedling from each treatment was produced good seedlings. Therefore, giving moss in the storage store can be used as an alternative method of seed storage duration $A$. lowii that are recalcitrant seed.

\section{Acknowledgements}

The authors would like to thank for the Seed Bank, Center for Plant Conservation, Botanic Gardens-Indonesia Institute of Science, which has facilitated us a greenhouse, media, the equipment, and materials research.

\section{References}

[1] K. Fern, "Usseful tropical plantsArtocarpuslowii. [Internet]. 2015. accessed on September 10 th, 2015 from http://tropical.theferns.info/ viewtropical.php?id=Artocar-pus+lowii".

[2] Yayasan Kehati Prosea, "BAHASA ILMIAH DALAM TEKS IKLAN BAHASA INDONESIA DAN BAHASA JERMAN Artocarpus. Internet. 2015. accessed on September 2, 2015 from http://www.proseanet.org/prohati2/browser.php? docsid=392. 2015. in Bahasa Indonesia".

[3] A. Tomar, A. Kumar, and S. Tripathi, "Seed germination behavior inArtocarpuslakoochaRoxb," Indion Forester, vol. 3, pp. 325-332, 2014.

[4] D. F. DJAM'AN, "Cryopreservation of dammar (Agathis damara Salisb.) seeds in liquid nitrogen," Biodiversitas, Journal of Biological Diversity, vol. 7, no. 2, pp. 164-167, 2006.

[5] FT. Bonner, "Commercial seed supply of recalcitrant and intermediate seed: present solutions to the storage problem," in Intermediate/Recalcitrant Tropical Forest Tree Seeds, Humlebaek, Denmark: Tome and DANIDA Forest Seed Centre, AS. Ouedrago, K. Poulsen, and F. Stubsgaard, Eds., pp. 27-33, Tome and DANIDA Forest Seed Centre, Denmark, 1996.

[6] MW. King, Roberts EH. The storage of recalcitrant seeds-achievements and possible approaches, IBPGR Secretariat, Rome, 1979.

[7] PennState Cooperative Extension-College of Agricultural Science. Introduction to organic vegetables-seed and seedling biology, PennState, Pennsylvania, 2012. 
[8] DK. Binawati, Pengaruh media tonam terhadap pertumbuhan anggrek bulan (Phalaenopsis sp.) aklimatisasi dalam plenty. [The effect of planting media on Phalaenopsis sp. growth in plenty acclimatization] Wohana, vol. 1, 60-68. [in Bahasa Indonesia], 1, 2012, [in Bahasa Indonesia]. 